\title{
SGP Cloud and Land Surface Interaction Campaign (CLASIC):
}

\section{Measurement Platforms}

June 2007

Mark A. Miller, Principal Investigator

and

The CLASIC Steering Committee:

Roni Avissar, Larry Berg, Sylvia Edgerton, Marc Fischer, Tom Jackson, Bill Kustas, Pete Lamb, Greg McFarquhar, Qilong Min, Beat Schmid, Margaret Torn, and Dave Turner

Work supported by the U.S. Department of Energy, Office of Science, Office of Biological and Environmental Research 


\section{Contents}

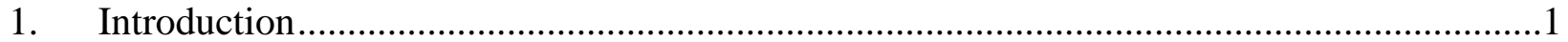

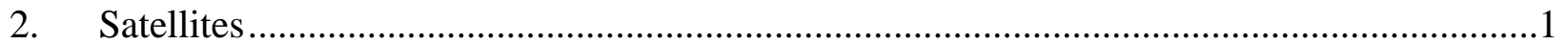

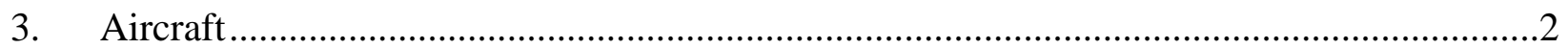

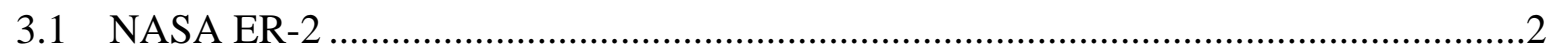

3.2 CIRPAS Twin Otter ............................................................................................

3.3 Twin-Otter International ................................................................................................

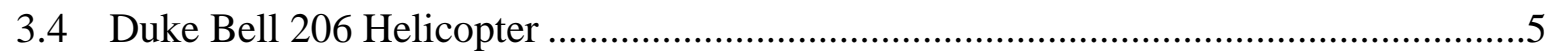

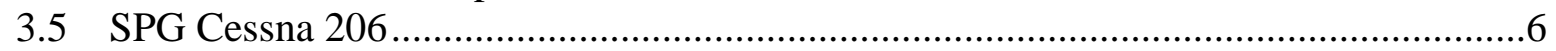

3.6 CHAPS Aircraft (G-1 and NASA King Air) .......................................................

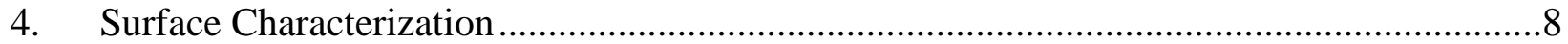

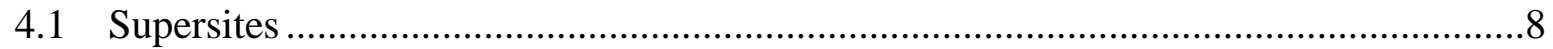

4.2 Carbon Flux Measurements ................................................................................

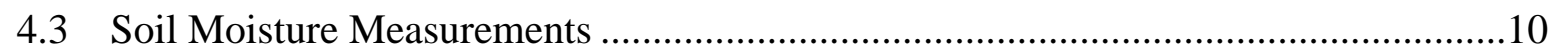

4.4 Land Cover and Vegetation Products .......................................................................10

4.5 Land Surface Satellite Remote Sensing Data .................................................................11

4.5.1 WindSat................................................................................................11

4.5.2 Advanced Microwave Scanning Radiometer......................................................11

4.5.3 Special Sensor Microwave Imager .....................................................................12

4.5.4 Envisat Advanced Synthetic Aperture Radar ……………………………........13

4.5.5 Terra Sensors ...........................................................................................14

4.5.6 Landsat Thematic Mapper ...........................................................................16

4.5.7 Advanced Wide Field Sensor.............................................................................16

4.6 Aircraft-Based Microwave Remote Sensing of Soil Moisture ......................................16

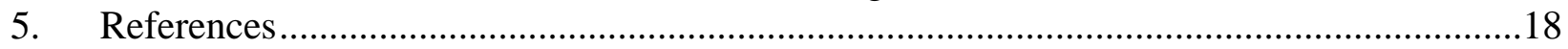

\section{Tables}

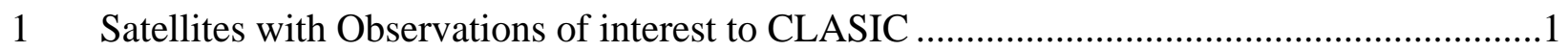

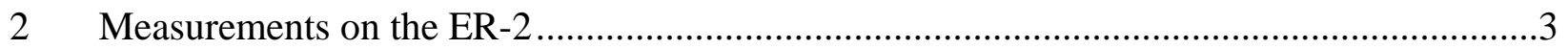

3 CIRPAS Twin Otter aircraft measurements for CLASIC...........................................................

4 Duplicate instruments sampling from both the CVI and non-CVI inlets ...............................

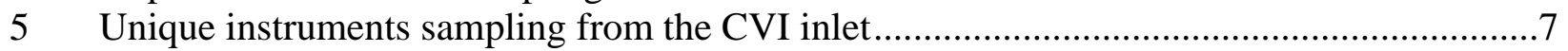

$6 \quad$ Unique instruments sampling from the non-CVI inlet ....................................................

7 Aerosol and cloud droplet sizing instruments mounted on the of the G-1 ….........................

8 Standard meteorological measurements ............................................................................

9 Measurements to be made from the NASA King Air Be-200 ….........................................

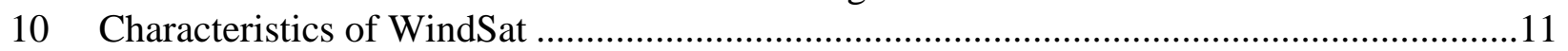

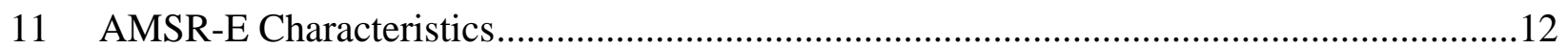

12 SSM/I Characteristics ………………………........................................................13

13 Specifications for ASAR Image Mode Swaths.............................................................14

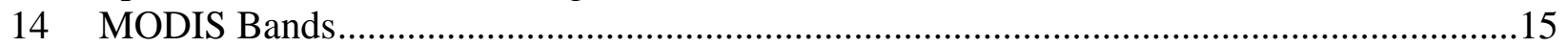

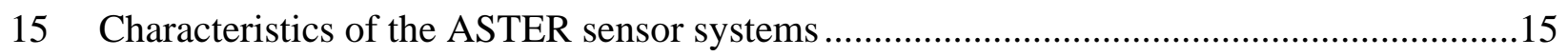

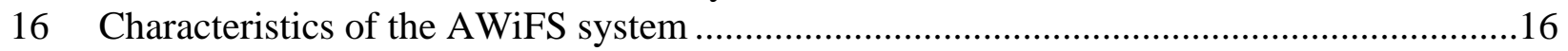

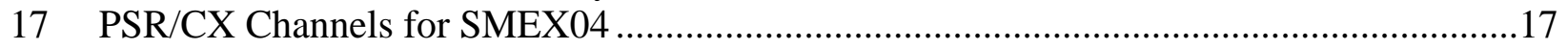

18 PSR Flightline and Mapping Specifications for SMEX04 ..................................................17 


\section{Introduction}

The Cloud and Land Surface Interaction Campaign (CLASIC) will be conducted from June 8 to June 30, 2007, at the U.S. Department of Energy's Atmospheric Radiation Measurement (ARM) Climate Research Facility (ACRF) Southern Great Plains (SGP) site. Data will be collected using eight aircraft equipped with a variety of specialized sensors, four specially instrumented surface sites, and two prototype surface radar systems. The architecture of CLASIC includes a high-altitude surveillance aircraft and enhanced vertical thermodynamic and wind profile measurements that will characterize the synoptic scale structure of the clouds and the land surface within the ACRF SGP site. Mesoscale and microscale structures will be sampled with a variety of aircraft, surface, and radar observations.

An overview of the measurement platforms that will be used during the CLASIC are described in the following sections. The coordination of measurements, especially as it relates to aircraft flight plans, will be discussed in the CLASIC Implementation Plan.

\section{Satellites}

A key element of CLASIC is integration with satellite observations, which potentially can extend the results of the experiment to other similar regions. Efforts will be made to coordinate observations, particularly aircraft, with satellite overpass times. Active and passive satellites that may provide data for CLASIC are summarized in Table 1. Additional satellites that may be particularly useful for assessing land characteristics are described in Section 4.5.

Table 1. Satellites with Observations of interest to CLASIC

\begin{tabular}{|c|c|c|c|}
\hline Satellite & Resolution & Orbital Characteristics & $\begin{array}{c}\text { Approximate } \\
\text { Overpass Times }\end{array}$ \\
\hline MODIS-Terra & $\begin{array}{l}2330 \mathrm{~km} \text { (cross track) by } \\
10 \mathrm{~km} \text { (along track at } \\
\text { nadir) }\end{array}$ & $\begin{array}{l}\text { sun-synchronous, near- } \\
\text { polar, circular }\end{array}$ & $\begin{array}{l}11 \mathrm{am}-1 \mathrm{pm} \text { and } \\
10 \mathrm{am}-12 \mathrm{pm}\end{array}$ \\
\hline MODIS-Aqua & $\begin{array}{l}2330 \mathrm{~km} \text { (cross track) by } \\
10 \mathrm{~km} \text { (along track at } \\
\text { nadir) }\end{array}$ & $\begin{array}{l}\text { sun-synchronous, near- } \\
\text { polar, circular }\end{array}$ & $\begin{array}{l}\text { AIRS/AMSU- } \\
\text { A/HSB } \\
\text { AMSR-R } \\
\text { CERES } \\
\text { MODIS }\end{array}$ \\
\hline Cloudsat & $\begin{array}{l}\text { 1.4-km x 2.5-km } \\
\text { (horizontal) } \\
240 \mathrm{~m} \text { (vertical) } \\
\text {-26 dBz Minimum } \\
\text { detectable signal }\end{array}$ & polar & Cloud radar \\
\hline Calipso & $\begin{array}{l}0.33 \mathrm{~km} \text { (horizontal } \\
\text { below 8-km altitude) } \\
30 \mathrm{~m} \text { (vertical } 532 \mathrm{~nm} \text { ) } \\
60 \mathrm{~m} \text { (vertical } 1064 \mathrm{~nm} \text { ) }\end{array}$ & polar & Two lidars \\
\hline \multicolumn{4}{|c|}{$\begin{array}{l}\text { A/HSB - humidity sounder for Brazil } \\
\text { AIRS - atmospheric infrared sounder } \\
\text { AMSR-R - advanced microwave scanning radiometer } \\
\text { AMSU - advanced microwave sounding unit } \\
\text { CERES - Clouds and the Earth’s Radiant Energy System } \\
\text { MODIS - moderate-resolution imaging spectroradiometer }\end{array}$} \\
\hline
\end{tabular}




\section{Aircraft}

The seven research aircraft that will be used during CLASIC have complementary capabilities. The aircraft solely dedicated to CLASIC are

- the National Aeronautics and Space Administration (NASA) ER-2, for high resolution measurement of three-dimensional cloud field boundaries, retrieved measures of cloud properties, and surface properties and soil moisture

- $\quad$ the Center for Interdisciplinary Remotely-Piloted Aircraft Studies (CIRPAS) Twin Otter for measurements of aerosol, meteorology, and chemistry

- the Twin Otter International (TOI) with the passive and active L- and S-band (PALS) for remote measurements of soil moisture

- the Duke University Helicopter Observation Platform (HOP) for measurements of heat, moisture, and carbon fluxes

- the Cessna 206, for measurements of aerosol chemistry and carbon dioxide.

In addition, two aircraft dedicated to the Cumulus Humilis Aerosol Plume Study (CHAPS) will provide useful information. These aircraft are the U.S. Department of Energy (DOE) Gulfstream-1 (G-1) for measuring aerosol, meteorology, and chemistry; and the NASA King Air with a high spectral resolution lidar.

\subsection{NASA ER-2}

The Lockheed ER-2 \#809 high-altitude aircraft, a civilian version of the Air Force U-2 reconnaissance platform, is owned and operated by NASA and based at Dryden Flight Research Center (http://www.nasa.gov/centers/dryden/home/index.html). The plane can attain altitudes in excess of $21 \mathrm{~km}(70,000 \mathrm{ft})$ and has been used in multiple airborne remote sensing field campaigns since 1971 (e.g., the 2005 Tropical Clouds and Systems Processes Study, the 2001 Convection and Moisture Experiment-4, and the 1993 Central Equatorial Pacific Experiment). During CLASIC, the ER-2 will be based in Houston, Texas, and will perform 45 to 72 research flight hours between June 9 and 30, 2007, depending on research and mission conditions. The ER-2 will fly over and around the ACRF SGP site. Observations on the ER-2 will provide a comprehensive data set that characterizes the three-dimensional cloud field boundaries, cloud properties, precipitation, and surface properties. Some flights also are planned to provide data for evaluating retrieval algorithms for instruments included on the A-train satellites. Instruments on the ER-2 to be used during CLASIC, as detailed in Table 2, include the cloud radar system, ER-2 Doppler radar, cloud physics lidar, moderate-resolution imaging spectroradiometer (MODIS) airborne simulator (MAS), and National Oceanic and Atmospheric Administration (NOAA) polarimetric scanning radiometer (PSR). 
Table 2. Measurements on the ER-2

\begin{tabular}{|c|c|c|c|}
\hline Instrument & "Description & Products & PI or Group \\
\hline $\begin{array}{l}\text { Cloud Radar System } \\
\text { W-band } 94.155 \mathrm{GHz} \\
\text { radar }\end{array}$ & $\begin{array}{l}\text { W-band }(94.155 \mathrm{GHz}) \\
\text { Doppler radar with } \\
\text { polarization capability }\end{array}$ & $\begin{array}{l}\text { Vertical profiles of calibrated } \mathrm{Z}, \mathrm{V}_{\mathrm{dop}} \text {, } \\
\text { estimated IWC and linear } \\
\text { depolarization ratio at } 5 \mathrm{~s} \text { resolution }\end{array}$ & $\begin{array}{l}\text { G. Heymsfield, } \\
\text { NASA Goddard } \\
\text { Space Flight Center }\end{array}$ \\
\hline ER-2 Doppler Radar & $\begin{array}{l}\text { X-band (9.6 GHz) fully- } \\
\text { coherent pulsed Doppler radar } \\
\text { with two antennas in nadir and } \\
\text { forward direction }\end{array}$ & $\begin{array}{l}\text { Nadir \& forward beam: Vertical } \\
\text { profiles of calibrated } \mathrm{Z}, \mathrm{V}_{\text {dop }} \text { and } \\
\text { Doppler spectral width at } 5 \mathrm{~s} \\
\text { resolution. Forward beam, Vertical } \\
\text { profile of linear depolarization ratio }\end{array}$ & $\begin{array}{l}\text { G. Heymsfield, } \\
\text { NASA Goddard } \\
\text { Space Flight Center }\end{array}$ \\
\hline Cloud Physics Lidar & $\begin{array}{l}\text { Solid-state Nd:YVO4 laser } \\
\text { operating at 1064, } 532 \text { and } \\
355 \mathrm{~nm} ; 5 \mathrm{kHz} \text { repetition rate } \\
\text { and output energy of } 50 \mu \mathrm{J} \\
(1064 \mathrm{~nm}), 25 \mu \mathrm{J}(532 \mathrm{~nm}) \\
\text { and } 50 \mu \mathrm{J}(355 \mathrm{~nm})\end{array}$ & $\begin{array}{l}\text { Vertical profiles of attenuated } \\
\text { backscatter coefficient, } \\
\text { depolarization ratio, extinction to } \\
\text { backscatter ratio, cloud \& aerosol } \\
\text { extinction, cloud \& aerosol } \\
\text { boundaries and cloud particle size for } \\
\text { ice clouds; } \tau \text { as function of time }\end{array}$ & $\begin{array}{l}\text { M. McGill, NASA } \\
\text { Goddard Space Flight } \\
\text { Center }\end{array}$ \\
\hline $\begin{array}{l}\text { MODIS Airborne } \\
\text { Simulator (MAS) }\end{array}$ & $\begin{array}{l}\text { Multi-spectral radiometer } \\
\text { operating at } 50 \text { bands in } \\
\text { infrared, near infrared and } \\
\text { visible from } 0.445 \mu \mathrm{m} \text { to } \\
14.428 \mu \mathrm{m}\end{array}$ & $\begin{array}{l}\text { Calibrated and geolocated spectral } \\
\text { radiances for } 50 \text { MAS channels; } \\
\text { Derived products of } \tau, \mathrm{r}_{\mathrm{e}} \text {, cloud top } \\
\text { height/temperature, cloud fraction, } \\
\text { cloud phase, and separated } \\
\text { aerosol/cloud } \tau\end{array}$ & $\begin{array}{l}\text { J. Myers, NASA } \\
\text { Ames } \\
\text { M. King and S. } \\
\text { Platnick, NASA } \\
\text { Goddard }\end{array}$ \\
\hline $\begin{array}{l}\text { Polarimetric } \\
\text { Scanning } \\
\text { Radiometer (PSR) }\end{array}$ & $\begin{array}{l}\text { C-band (6.9 GHz) and X-band } \\
(10.7 \mathrm{GHz}) \text { radiometers }\end{array}$ & $\begin{array}{l}\text { Surface brightness temperature, soil } \\
\text { moisture }\end{array}$ & $\begin{array}{l}\text { A. Gasiewski, NOAA } \\
\text { Center for } \\
\text { Environmental } \\
\text { Technology }\end{array}$ \\
\hline
\end{tabular}

\subsection{CIRPAS Twin Otter}

The Twin Otter is operated by the CIRPAS in Marina, California (Bluth et al. 1996; Bane et al. 2004). During CLASIC, the Twin Otter will be based in Oklahoma at the Ponca City Airport and will perform 45 hours of flight research. All flight patterns will be anchored at the ACRF SGP Central Facility $\left(36.60^{\circ} \mathrm{N}, 97.48^{\circ} \mathrm{E}, 319 \mathrm{~m}\right), 32 \mathrm{~km}$ west of Ponca City. The maximum flight altitude will be 17,500 ft. The CLASIC payload consists of internal and external probes making detailed in situ cloud, aerosol, carbon cycle gases, and meteorological measurements. A detailed list of the instrumentation is given in Table 3. All cabin in situ instrumentation aboard the Twin Otter samples from a shrouded intake whose inlet passing efficiency was tested in airborne and wind tunnel experiments by Hegg et al. (2005). No appreciable loss in efficiency was found for aerosol particles smaller than approximately $3.5 \mu \mathrm{m}$ diameter at the typical Twin Otter velocity of $50 \mathrm{~m} \mathrm{~s}^{-1}$. For larger particles, the efficiency decreases rapidly but levels off at an efficiency slightly better than 0.6 for particles $5.5 \mu \mathrm{m}$ diameter through the limit of their measurements at $9 \mu \mathrm{m}$. 
Table 3. CIRPAS Twin Otter aircraft measurements for CLASIC

\begin{tabular}{|c|c|c|}
\hline Available Measurement & Instrument & PI or Group \\
\hline Total aerosol number concentration & $\begin{array}{l}\text { Condensation Particle Counters (CPC) } \\
\text { Up to } 3\end{array}$ & CIRPAS \\
\hline $\begin{array}{l}\text { Aerosol/cloud size distribution } \\
d=0.1-2.5 \mu \mathrm{m} \\
d=0.8-80 \mu \mathrm{m}\end{array}$ & $\begin{array}{l}\text { Passive Cavity Aerosol Spectrometer Probe } \\
\text { (PCASP) } \\
\text { Cloud Aerosol and Precipitation Spectrometer } \\
\text { (CAPS) }\end{array}$ & CIRPAS \\
\hline $\begin{array}{l}\text { Aerosol/cloud size distribution } \\
\mathrm{d}=2.5-50 \mu \mathrm{m}\end{array}$ & Forward Scattering Spectrometer Probe & CIRPAS \\
\hline Cloud liquid water content & $\begin{array}{l}\text { Gerber PVM } \\
\text { Johnson probe on CAPS }\end{array}$ & CIRPAS \\
\hline $\begin{array}{l}\text { Aircraft state parameters: } \\
\text { Position } \\
\text { irspeed } \\
\text { Pressure altitude } \\
\text { Attitude (pitch, roll, yaw) } \\
\end{array}$ & Various instruments (with redundancy) & CIRPAS \\
\hline $\begin{array}{l}\text { Meteorological state parameters: } \\
\text { Dry-bulb temperature } \\
\text { Dew point temperature } \\
\text { Pot T, Equiv. Pot T } \\
\text { Pressure } \\
\text { Horizontal wind vector } \\
\text { Updraft velocities } \\
\text { Surface Temp }\end{array}$ & $\begin{array}{l}\text { Gust probe } \\
\text { Heiman KT18.95 }\end{array}$ & CIRPAS \\
\hline Aerosol scattering & $\begin{array}{l}\text { Total Sky Imager (TSI) Nephelometer } \\
(450,550,700 \mathrm{~nm}) \text { dry }\end{array}$ & $\begin{array}{l}\text { CIRPAS + J. Ogren } \\
\text { (NOAA) }\end{array}$ \\
\hline Aerosol absorption & $\begin{array}{l}\text { Soot Photometer } \\
\text { (PSAP, 467, 530, } 660 \mathrm{~nm} \text { ) dry }\end{array}$ & $\begin{array}{l}\text { CIRPAS+ J. Ogren } \\
\text { (NOAA) }\end{array}$ \\
\hline $\begin{array}{l}\text { Cloud condensation nuclei } \\
\text { supersaturation spectrum }\end{array}$ & CCN instrument & D. Collins (Texas A\&M) \\
\hline $\begin{array}{l}\text { Aerosol size distribution and } \\
\text { hygroscopicity }\end{array}$ & Tandem Differential Mobility Analyzer & D. Collins (Texas A\&M) \\
\hline $\begin{array}{l}\text { Cloud drop size distribution } \\
\mathrm{d}=2 \text { to } 150 \mu \mathrm{m}\end{array}$ & Phase-Doppler Interferometer (PDI) & $\begin{array}{l}\text { P. Chuang (UC Santa } \\
\text { Cruz) }\end{array}$ \\
\hline $\begin{array}{l}\mathrm{CO}_{2}, \mathrm{CO}, \mathrm{CH}_{4}, \mathrm{~N}_{2} \mathrm{O}, \mathrm{H}, \mathrm{SF}_{6},{ }^{13} \mathrm{C} \text { (in } \\
\mathrm{CO}_{2} \text { ) and }{ }^{18} \mathrm{O}\left(\text { in } \mathrm{CO}_{2}\right) \\
\text { Radon }\end{array}$ & $\begin{array}{l}\text { (1) 12-flask sampler } \\
\text { (2) continuous } \mathrm{CO}_{2} \\
\text { (3) tedlar bag sampler for Radon analysis }\end{array}$ & M. Torn (LBL) \\
\hline $\mathrm{CO}, \mathrm{CH}_{4}, \mathrm{~N}_{2} \mathrm{O}$ (all continuous) & Argus & $\begin{array}{l}\text { J. Lopez (NASA } \\
\text { ARC/BAERI) }\end{array}$ \\
\hline
\end{tabular}

\subsection{Twin-Otter International}

NASA supports a new aircraft-based PALS microwave sensor that combines both active and passive technologies for soil moisture applications. Current microwave models and retrieval algorithms have significant limitations in their treatment of different vegetation types and heterogeneous scenes (e.g., mixtures of grass, crops, trees, streams, and lakes) and quantitative treatment of algorithm scaling and error analysis for such heterogeneous scenes. Joint active and passive sensor measurements are needed over wide varieties of terrain to develop algorithms and parameterizations and extract optimum information from the combined data. These measurements will directly impact the design of dedicated soil moisture missions and development of methods to assimilate the data into land surface models. 
Microwave radiometry and radar are well-established techniques for surface remote sensing. Combining passive and active sensors provides complementary information contained in the surface emissivity and backscatter signatures, which can improve the accuracy of retrieval of geophysical parameters. Over land, it has been demonstrated that the radiometer and the radar both provide information for estimating soil moisture and vegetation water content (Bolten et al. 2003; Njoku et al. 2003).

The capability and scientific potential of PALS have been demonstrated through past field programs and associated research results for both soil moisture and ocean salinity applications (Narayan et al. 2004). A key limitation of the PALS (PALS-I) system was the use of a conical horn for the antenna. A PALS-II instrument has been modified for operation on a Twin Otter aircraft by replacing the antenna with an alternate design. During CLASIC, the goals for the PALS-II include (1) demonstrating the new antenna, (2) providing additional data sets for activepassive algorithm development and validation, and (3) conducting polarimetric analyses. In the past, missions were designed to include a set of flight lines over intensively sampled fields. Fields were located close together to minimize the number of flight lines. In addition, an altitude was selected that resulted in a footprint smaller than the typical field size of $800 \mathrm{~m}$. Current planning includes flight lines in both the Little Washita (LW) and Fort Cobb (FC) areas. The LW lines will link to the supersites and the previous experiments in this domain. The FC lines are being added to increase the potential range of both land cover and soil moisture conditions. The area selected includes numerous fields with the potential for providing irrigation (center pivot). It is unlikely that farmers would be irrigating at this time of year; however, they would be willing to irrigate if they were reimbursed for their costs. Preliminary discussions indicate that, if full profile irrigation is not required, irrigation could be completed in 6-12 hours. This guarantees that wet conditions can be observed, which are critical for PALS-II. In addition, it may be possible to observe a dry down time sequence, which is critical for many of the algorithm science questions.

Based upon available information, the Twin Otter ground speed will be between 150 and $300 \mathrm{~km} /$ hour. Using $200 \mathrm{~km} /$ hour, each of the LW lines will require about 15 minutes with turns, and the FC will require about 10 minutes. There should be adequate flight hours to support these lines. Additional lines are also possible, which might include both east and west (or north and south) headings of each line to mitigate radio frequency interference. In addition, more lines could be flown in the LW to provide more high-resolution map coverage. The final flight lines will be defined after all ground sampling locations are identified and additional participants in CLASIC have commented on the preliminary plan. It is especially desirable to coordinate relatively low altitude flights of the ER-2 with the TOI/PALS.

The data from the field experiments will be radiometrically calibrated and geolocated for distribution to the hydrology research community. Data analysis that correlates the PALS-II data with the in situ measurements will assess the utility of the polarimetric measurements.

\subsection{Duke Bell 206 Helicopter}

The Duke University HOP combines a slow sampling speed with a long duration at the designated sampling area, making this an excellent platform for boundary-layer (including entrainment-layer) flux studies. Since a helicopter can fly safely at low altitudes, HOP is an ideal platform to observe surface-layer fluxes. The scientific sensors currently mounted on the 
craft's nose include a prototype sonic anemometer developed by Kaijo in collaboration with the Japan Aerospace Exploration Agency to measure high frequency (40-Hz), three-dimensional turbulence up to a $60 \mathrm{~m} / \mathrm{s}$ airspeed (which is the operational top speed for the HOP). This variable is also measured at the same frequency with the Aventech AIMMS-20, a five-hole probe based on pressure fluctuations technology. Both sensors measure temperature fluctuations, and the AIMMS-20 provides air humidity with a newly designed sensor that has been adapted by Aventech exclusively for the HOP. The redundancy of turbulence measurement is intentional given the importance of this key atmospheric variable for the calculation of turbulent fluxes in the boundary (turbulent) layer. In addition, HOP is equipped with a Licor 7500 to measure water and carbon dioxide concentrations at high frequency. The total science payload capacity of the HOP is approximately 500 lbs. Since the current payload is well under this weight, HOP could accommodate additional instrumentation. Additional information on HOP is available at http://www.cee.duke.edu/research/hop/

During CLASIC, the HOP will provide fluxes of heat, moisture, and $\mathrm{CO}_{2}$ in the boundary layer. The helicopter will fly primarily in the vicinity of the three supersites, in a triangular configuration. On a given day, HOP will fly circuits around one supersite. It will then transit to another site to fly another set of circuits around that site on the next flight day. There are 100 flight hours available.

\subsection{SPG Cessna 206}

The Cessna flies approximately three flights per week on randomly selected days over the ACRF SGP site. These routine flights will continue through CLASIC. In addition, the carbon flux group will use the Cessna to augment its mission goals outlined for the Twin Otter. The aircraft routinely obtains vertical profiles of aerosol optical properties over the SGP site. The aerosol package measures light scattering, back scattering, and absorption at three wavelengths for particles with a diameter less than approximately 5 microns. It also measures submicron light scattering at one wavelength for three humidities to provide an indication of the hygroscopic nature of the aerosol. Non-aerosol instruments, which have been incorporated into the aerosol package, include a programmable flask package for obtaining samples of carbon dioxide and other trace gases at each flight level and continuous gas analyzers for carbon dioxide and ozone. Data from the more than 700 flights (as of September 2006) are available from the ACRF archive. The flight data are reviewed, checked for quality assurance, and submitted to the archive within two days of a flight.

Using an infrared gas analyzer from the surface to mid-troposphere (i.e., 5-7 km), the Cessna can measure continuous $\mathrm{CO}_{2}$ concentration profiles. Currently, the flights include a flask-based collection of trace gases (e.g., for $\mathrm{CO}, \mathrm{CH}_{4}$, and $13 \mathrm{CO}_{2}$ ) at several heights and the capability for measuring ${ }^{14} \mathrm{CO}_{2}$. This suite of trace gases, in combination with the $\mathrm{CO}_{2}$ profiles, provides comprehensive data for inverse methods that infer ecosystem carbon exchange and quantify anthropogenic combustion emissions. Additional airborne instruments available for use on the Cessna include

- large volume tedlar bags for air samples of atmospheric 222Radon

- continuous $\mathrm{CO}$ and $\mathrm{CH}_{4}$ measurements with tunable diode laser

- manual trapping of water vapor by an aircraft passenger. 
Additional information about the Cessna 206 can be found at http://www.cmdl.noaa.gov/aero/net/iap/index.html.

\subsection{CHAPS Aircraft (G-1 and NASA King Air)}

The DOE Gulfstream-1 (G-1) research aircraft and the NASA King Air Be-200 are the primary instrument platforms taking part in the DOE Atmospheric Science Program (ASP) CHAPS. Details on CHAPS can be found at the DOE ASP website (www.asp.bnl.gov/AerosolCumuliform.html). The primary goal of CHAPS is to characterize and contrast aerosols above, within, and below fields of fair-weather clouds. To address this goal, the G-1 will fly several transects through fields of cloud upwind and downwind of Oklahoma City. The sampling pattern used by the G-1 will be very similar to that used by the Twin Otter, with flight patterns below, within, and above the clouds. The NASA King Air will fly a pattern similar to the G-1, but at a single altitude approximately $8 \mathrm{~km}$ above the ground.

The G-1 will use a dual inlet sampling system, and will make use of two different aerosol inlets: one is a Brechtel Isokinetic inlet and the other is a counter flow virtual impactor (CVI) inlet. The CVI inlet selectively removes all aerosols from the sampling stream except for the cloud droplets. Nearly identical instrumentation will be used with each inlet to measure the aerosol scattering, absorption, size, and composition (see Tables 4-9 for instrumentation details). In addition, the number of Cloud Condensation Nuclei Counter (CCN) will be at two supersaturations. The NASA King Air carries a high spectral resolution lidar that will be used measure aerosol backscatter and extinction from near the surface to well above the fields of cumuli.

Table 4. Duplicate instruments sampling from both the CVI and non-CVI inlets

\begin{tabular}{||l|l||}
\hline \multicolumn{1}{|c|}{ Parameter } & \multicolumn{1}{c||}{ Instrument } \\
\hline Light-scattering coefficient & 3-wavelength nephelometers \\
\hline Aerosol absorption & 3-wavelength PSAP \\
\hline $\begin{array}{l}\text { Cloud condensation nuclei at fixed } \\
\text { supersaturation (2 per inlet, 4 total) }\end{array}$ & $\begin{array}{l}\text { Droplet Measurement Technology (DMT) Cloud Condensation Nuclei } \\
\text { Counter (CCN) }\end{array}$ \\
\hline $\begin{array}{l}\text { Submicron bulk OC, } \mathrm{SO}_{4}, \mathrm{NO}_{3}, \mathrm{Cl}, \mathrm{NH}_{4} \\
\mathrm{~g} \mathrm{~m}\left({ }^{-3}\right)\end{array}$ & Aerosol mass spectrometry \\
\hline Aerosol composition & Time-Resolved Aerosol Collector \\
\hline Particle Number & TSI Condensation Particle Counter (CPC) x 2 \\
\hline Aerosol absorption & Los Alamos Photo Acoustic \\
\hline \hline
\end{tabular}

Table 5. Unique instruments sampling from the CVI inlet

\begin{tabular}{|l|l||}
\hline \multicolumn{1}{|c|}{ Parameter } & \multicolumn{1}{c|}{ Instrument } \\
\hline Aerosol size distribution & Fast Integrated Mobility Spectrometer \\
\hline \hline
\end{tabular}

Table 6. Unique instruments sampling from the non-CVI inlet

\begin{tabular}{||l|l||}
\hline \multicolumn{1}{|c|}{ Parameter } & \multicolumn{1}{|c||}{ Instrument } \\
\hline Submicron aerosol size & SMPS \\
\hline Carbon Monoxide $(\mathrm{CO})$ & VacuumUV \\
\hline Sulfur Dioxide $\left(\mathrm{SO}_{2}\right)$ & UV Pulsed Fluorescence \\
\hline Ozone $\left(\mathrm{O}_{3}\right)$ & B2B Ozone Analyzer \\
\hline Water Vapor & TDL $\mathrm{H}_{2} \mathrm{O}$ \\
\hline
\end{tabular}


Table 7. Aerosol and cloud droplet sizing instruments mounted on the of the G-1

\begin{tabular}{|l|l||}
\hline \multicolumn{1}{|c|}{ Parameter } & \multicolumn{1}{c||}{ Instrument } \\
\hline Aerosol size distribution & PCASP \\
\hline Aerosol and Droplet Size Distribution & DMT Cloud Aerosol and Precipitation Spectrometer (CAPS) \\
\hline
\end{tabular}

Table 8. Standard meteorological measurements

\begin{tabular}{|l|l|}
\hline \multicolumn{1}{|c|}{ Parameter } & \multicolumn{1}{c|}{ Instrument } \\
\hline $\begin{array}{l}\text { Turbulent wind components } \\
(\mathrm{u}-\mathrm{v}-\mathrm{-}, \mathrm{w}-\text { - })\end{array}$ & Gust Probe \\
\hline Liquid water concentration (LWC) & Gerber PVM-100A Probe (optical light scattering) \\
\hline Air Temperature & Platinum Resistance Thermometer \\
\hline Dewpoint & Chilled Mirror \\
\hline Altitude & Barometric/GPS \\
\hline Position & GPS \\
\hline
\end{tabular}

Table 9. Measurements to be made from the NASA King Air Be-200

\begin{tabular}{|l|c|c|}
\hline \multicolumn{1}{|c|}{ Parameter } & $\begin{array}{c}\text { Horizontal Resolution } \\
(\mathbf{m})\end{array}$ & $\begin{array}{c}\text { Vertical Resolution } \\
(\mathbf{m})\end{array}$ \\
\hline $532 \mathrm{~nm}$ backscatter & 50 & 30 \\
\hline $532 \mathrm{~nm}$ aerosol depolarization & 50 & 30 \\
\hline $532 \mathrm{~nm}$ extinction & 1500 & 300 \\
\hline $1064 \mathrm{~nm}$ backscatter & 50 & 30 \\
\hline $1064 \mathrm{~nm}$ aerosol depolarization & 50 & 30 \\
\hline
\end{tabular}

\section{Surface Characterization}

The overarching objectives of CLASIC require flux and state measurements throughout the dominant land covers and distributed over the geographic domain. These efforts will determine the level up-scaling/aggregation required to understand the impact of landscape changes affecting energy balance/flux partitioning and impact on cloud/atmospheric dynamics. Critical factors need to be monitored to predict the sensible and latent heat fluxes at an acceptable accuracy for predicting the onset of cloud formation. These factors include canopy temperature, vapor pressure deficit, and soil moisture availability. Hyper-spectral and broadband spectral indices will be used to establish the parameters necessary for accurate modeling of both energy and $\mathrm{CO}_{2}$ fluxes. These include leaf area index, green and dry standing biomass, biomass residue, canopy height, and maximum light-use efficiency. Digital cameras also will be deployed at selected sites to monitor, in near-real time, the surface conditions, the cloud type, and the onset of cloud formation. The camera will be useful for evaluating the effect of diffuse light on carbon uptake at various stages of surface conditions.

\subsection{Supersites}

A combination of intensive point/tower observations, higher resolution aircraft tracks and maps, and satellite-derived products will be distributed at three locations (supersites) distributed over the SGP site that have been selected to represent the dominant land covers, optimize resources, and satisfy larger scale objectives. Measurements and protocols at each location will be standardized. Capturing and providing high quality flux data for the dominant land cover conditions in the domain is a top priority. These conditions are winter wheat, grassland, and forest. 
The three supersites will be located at the ACRF SGP Central Facility; LW; and EF21 (FS), which is a forest dominated area. The Central Facility has extensive instrumentation, a long period of record, and is highly representative of its particular area of the SGP site. The LW was selected as a focal area because of the extensive hydrologic information available, the Agricultural Research Service Micronet and stream flow gages. The LW also has been the focus of numerous surface flux and soil moisture studies (Kustas and Jackson 1999) and is a mixedland use area. At LW and FS, a simple suite of cloud and atmospheric measurements will be made. Cloud occurrence, cloud base height, and precipitation also will be measured. The general locations of the three sites were chosen to form a triangle that could be flown by the Duke University Helicopter flux system for scaling studies. Agricultural Research Service will lead the efforts in LW. Measurements from aircraft and the surface will provide a companion data set to the hydrologic community providing information for assessing feedbacks between ground water and the atmosphere. Around each supersite, replicate towers will help quantify flux variance within each land use and provide useful statistics for examining differences in fluxes across land use.

The satellite-based flux information and the MAS data that will be collected by the ER-2 during CLASIC are needed to provide long-term validation of the PSR products and resolve in-field variability in vegetation/moisture conditions at each site. If pixel resolution over the areas surrounding the tower networks can be attained at an approximately 25-m resolution, these data will provide high enough resolution to properly sample flux-footprint contributions to tower measurements. In addition, centering overpass times near midmorning (i.e., approximately1030 central standard time) over the supersite under intensive observation provides the most useful information for thermal remote sensing-based flux modeling.

\subsection{Carbon Flux Measurements}

The objectives of the carbon program in CLASIC are to characterize regional carbon fluxes, compare the top down (atmospheric) and bottom up (ecological) modeling systems for carbon and heat flux, and establish the relationship between the carbon cycle and the water cycle in influencing the evolution of cumulus cloud evolution. The supersites will link the observed carbon fluxes, which represent plant responses, to atmospheric structure. Carbon flux towers will be deployed at the two non-Central Facility supersites. These eddy correlation systems would also measure the latent and sensible heat fluxes. Generally, two techniques are used to quantify the carbon flux. The first is through the eddy correlation technique, which is currently used to measure the carbon fluxes at the Central Facility; and the second is at the leaf level using infrared gas analyzers. The first technique is known as "stand level" and the second as "leaf level." Fortunately, much is known about the "leaf level” processes in agricultural growths, such as winter wheat. This suggests that "stand-level" measurements may be a prime focus for CLASIC, due to budget constraints, but that "leaf level" studies would be desirable if the budget permits.

The Central Facility will provide a thorough characterization of the clouds, precipitation, and radiation from routine observations. It will serve as the primary source of information about cloud and carbon flux feedbacks. 


\subsection{Soil Moisture Measurements}

During CLASIC, intensive soil moisture measurements will be made for specific regions within the domain using in situ networks and new aircraft sensors. In addition, intensive soil temperature and measures of ground heat flux also will be made using newly designed soil heat flux probes. Soil moisture retrieval algorithms and processing of PSR data sets will provide large-scale soil moisture data.

The location of the soil moisture influencing flux observations, boundary layer development, and cloud formation may originate at some distance from a tower or point location. Therefore, spatially distributed map products of soil moisture are critical to the success of the project. The only observational technique that can provide these at acceptable spatial resolutions and temporal frequencies is aircraft-based microwave remote sensing. Over larger scales, information from satellite products may be useful. Currently, satellite soil moisture products are available from NASA at a nominal spatial resolution of $25 \mathrm{~km}$. Although these methods will be of some value to CLASIC, other methods will be explored. These include enhanced spatial resolution approaches using higher resolution sensors and improved, regionally optimized, soil moisture retrieval algorithms.

The PSR will be the key sensor in providing the required soil moisture product. However, several steps are involved in translating the sensor data into soil moisture (Bindlish et al. 2006). These require some level of ground-based sampling for calibrating and some lower altitude/higher spatial resolution flights for both calibrating and scaling. Frequent coverage of both the domain (high altitude) and LW (low altitude) are needed. Sources of ground-based calibration/validation data will include intensive studies and existing networks in the LW and FC Reservoir. For the Central Facility and FS, a temporary network of automated in situ sensors will be deployed.

A new aircraft instrument (PALS) that combines both active and passive technologies for soil moisture applications is being supported by NASA. This instrument, in its current state, is not designed for regional mapping but will be used in intensive soil moisture studies for specific regions within the domain. Ground-based sampling to support this instrument will require sampling large fields, typically a quarter section in size, that include diverse cover/use types. These fields will be co-located within smaller domains to optimize aircraft resources. Lower altitude flights of the ER-2 over the watersheds of interest would contribute to scaling/validation investigations of soil moisture and the remote sensing-based flux modeling validation.

\subsection{Land Cover and Vegetation Products}

Land cover and vegetation products for the entire CLASIC domain are critical information needed for the suite of objectives/science questions being addressed. These products will be developed from multi-date imagery collected by several satellites and the MAS on the ER-2. The Landsat Thematic Mapper ${ }^{\mathrm{TM}}$ products are valuable because of the minimal processing, low cost, and adequate spatial resolution. However, the probability is low that these products will be in operation during the project.

To provide accurate land cover and vegetation index data, ground-based surveys, reflectance measurements, and biomass sampling will be conducted during the campaign. Digital cameras programmed to observe both site (ground and surface conditions) and sky conditions will be used 
to detect the type and onset of cloud formation. The development of geographic resources will include land cover, crop residue, hyper spectral reflectance, the earth's normalized-difference vegetative index and leaf area index products for each land use. Aircraft observations will provide the critical bridge for scaling and integrating the point observations to the coarse satellite footprints. In addition, higher resolution aircraft soil moisture products are of value in more intensive hydrologic investigations.

\subsection{Land Surface Satellite Remote Sensing Data}

\subsubsection{WindSat}

WindSat is a satellite-based multi-frequency polarimetric microwave radiometer developed by the Naval Research Laboratory for the U.S. Navy and the National Polar-orbiting Operational Environmental Satellite System Integrated Program Office (Gaiser et al. 2004). It is one of the two primary instruments on the Coriolis satellite. The Coriolis satellite was successfully launched on January 6, 2003, with an expected life cycle of three years.

The WindSat radiometer operates at nominal frequencies of 6.8, 10.7, 18.7, 23.8, and $37 \mathrm{GHz}$. Using a conically-scanned 1.83-m offset parabolic reflector with multiple feeds, the WindSat covers a 1025-km active swath (based on an altitude of $830 \mathrm{~km}$ ) and provides two looks at both fore $(1025 \mathrm{~km})$ and aft (350 km) views of the swath. The nominal earth incidence angle is in the range of $50^{\circ}-55^{\circ}$. The inclination of the WindSat orbit is $98^{\circ}$. It has a sun synchronous polar orbit with an ascending node at 6:00 p.m. local standard time (LST) and a descending node at 6:00 a.m. LST.

The WindSat has similar frequencies to the advanced microwave scanning radiometers on the advanced microwave scanning radiometer-Earth Observing System (AMSR-E), with the addition of full polarization for 10.7, 18.7, and $37.0 \mathrm{GHz}$ and the lack of an $89.0-\mathrm{GHz}$ channel. The characteristics of the WindSat radiometer are listed in Table 10. Initially, the methods developed for algorithm development and validations for AMSR-E may be applied to WindSat with minimal modifications. The coverage dates and times of WindSat during the Soil Moisture Experiment 2005 and Polarimetry Land Experiment (SMEX05/POLEX) are summarized in Table 10. Note that the average morning overpass time is 7:36 a.m. LST.

Table 10. Characteristics of WindSat

\begin{tabular}{|c|l|c|c|c||}
\hline $\begin{array}{c}\text { Frequency } \\
\text { (GHz) }\end{array}$ & Polarization & $\begin{array}{c}\text { Incidence } \\
\text { Angle (Deg.) }\end{array}$ & $\begin{array}{c}\text { Footprint } \\
\text { (Km) }\end{array}$ & $\begin{array}{c}\text { Fore/Aft } \\
\text { Swath (Km) }\end{array}$ \\
\hline 6.8 & V, H & 53.5 & $40 \times 60$ & $1025 / 350$ \\
\hline 10.7 & V, H, U 4 & 49.9 & $25 \times 38$ & $1025 / 350$ \\
\hline 18.7 & V, H, U, 4 & 55.3 & $16 \times 27$ & $1025 / 350$ \\
\hline 23.8 & V, H & 53.0 & $12 \times 20$ & $1025 / 350$ \\
\hline 37.0 & V, H, U 4 & 53.0 & $8 \times 13$ & $1025 / 350$ \\
\hline
\end{tabular}

\subsubsection{Advanced Microwave Scanning Radiometer}

The AMSR-E was launched on the Aqua satellite (http://weather.msfc.nasa.gov/AMSR/) in May 2002. Algorithm development and validations of AMSR-E soil moisture products are important components of the SMEX (Njoku et al. 2003). 
As shown in Table 11, the lowest frequency of AMSR-E is $6.9 \mathrm{GHz}$ (C band). However, studies indicate widespread radio frequency interference exists in the $\mathrm{C}$ band channels ( $\mathrm{Li}$ et al. 2004). Therefore, it is likely that the most useful channels for soil moisture will be those operating at the slightly higher $\mathrm{X}$ band. The viewing angle of AMSR is a constant $55^{\circ}$. Details on AMSR-E can be found at http://weather.msfc.nasa.gov/AMSR/. The average local overpass times in the SMEX05/POLEX region at this time of year are 3:10 and 14:10.

Table 11. AMSR-E Characteristics

\begin{tabular}{|c|c|c|c|}
\hline $\begin{array}{c}\text { Frequency } \\
\text { (GHz) }\end{array}$ & Polarization & $\begin{array}{c}\text { Horizontal } \\
\text { Resolution (km) }\end{array}$ & $\begin{array}{c}\text { Swath } \\
(\mathbf{k m})\end{array}$ \\
\hline 6.925 & $\mathrm{~V}, \mathrm{H}$ & 75 & 1445 \\
\hline 10.65 & $\mathrm{~V}, \mathrm{H}$ & 48 & 1445 \\
\hline 18.7 & $\mathrm{~V}, \mathrm{H}$ & 271445 & \\
\hline 23.8 & $\mathrm{~V}, \mathrm{H}$ & 311445 & \\
\hline 36.5 & $\mathrm{~V}, \mathrm{H}$ & 141445 & \\
\hline 89.0 & $\mathrm{~V}, \mathrm{H}$ & 6 & 1445 \\
\hline
\end{tabular}

During SMEX05/POLEX, Aqua included the following additional instruments of potential value to investigators:

- The atmospheric infrared sounder is a high-resolution instrument, which measures upwelling infrared (IR) radiances at 2378 frequencies ranging from 3.74 and 15.4 micrometers.

- The advanced microwave sounding unit is a passive scanning microwave radiometer consisting of two sensor units, A1 and A2, with a total of 15 discrete channels operating over the frequency range of 50 to $89 \mathrm{GHZ}$. The advanced microwave sounding unit operates in conjunction with the atmospheric infrared sounder and the humidity sounder for Brazil instruments to provide atmospheric temperature and water vapor data both in cloudy and cloud-free areas.

- Clouds and the Earth’s Radiant Energy System is a broadband scanning radiometer with three detector channels: 0.3 to 5.0 micrometers, 8.0 to 12.0 micrometers, and 0.3 to 50 micrometers.

- MODIS is a passive imaging spectroradiometer. The instrument scans a cross-track swath of $2330 \mathrm{~km}$ using 36 discrete spectral bands between 0.41 and 14.2 micrometers.

\subsubsection{Special Sensor Microwave Imager}

Special sensor microwave/imager (SSM/I) satellites have been collecting global observations since 1987. The SSM/I satellite data can only provide soil moisture under restricted conditions because the frequencies (see Table 12) were not selected for land applications (Jackson 1997; Jackson et al. 2002; Teng et al. 1993). The viewing angle of the SSM/I is 53.1 . 
Table 12. SSM/I Characteristics

\begin{tabular}{|c|l|c|c|}
\hline $\begin{array}{c}\text { Frequency } \\
\text { (GHz) }\end{array}$ & Polarization & $\begin{array}{c}\text { Spatial } \\
\text { Resolution } \\
(\mathbf{k m})\end{array}$ & Swath (km) \\
\hline 19.4 & H and V & $69 \times 43$ & 1200 \\
\hline 22.2 & V & $60 \times 40$ & 1200 \\
\hline 37.0 & H and V & $37 \times 28$ & 1200 \\
\hline 85.5 & H and V & $15 \times 13$ & 1200 \\
\hline
\end{tabular}

During SMEX05/POLEX, as many as four satellites operated with the SSM/I on board. The local ascending equatorial crossing times of the three currently available satellites are F13 (17:54), F14 (20:46), and F15 (21:20). The F16 (07:54) was launched in October 2003. SSM/I data are useful in some aspects of algorithm development and provide a cross reference to equivalent channels on the WindSat and AMSR-E instruments. SSM/I data are freely available to users through http://www.ncdc.noaa.gov/oa/ncdc.html. As in past experiments, the data will be subset and repackaged for this experiment.

\subsubsection{Envisat Advanced Synthetic Aperture Radar}

The Envisat satellite was launched by the European Space Agency in March 2002 (http://envisat.esa.int/). It is designed to provide earth observations using a suite of remote sensing instruments. Of particular interest to soil moisture and hydrology is the inclusion of the advanced synthetic apertureradar (ASAR) that will provide continuity to both the ERS-1 and ERS-2 mission SARs and next generation capabilities. Envisat also has a visible and near infrared imaging system: the medium resolution imaging spectrometer (MERIS). Envisat has a sun synchronous polar orbit. The exact repeat cycle for a specific scene and sensor configuration is 35 days.

The ASAR is a C band instrument, which is the same frequency as the ERS instrument. Unlike the ERS satellites that have a fixed angle of incidence $\left(23^{\circ}\right)$, the ASAR has a wider range of choices that can provide more frequent coverage and a variety of incidence angles. ASAR Image Mode will provide data acquisition in the seven different swath positions listed in Table 13, giving incidence angles ranging from $15^{\circ}$ to $45^{\circ}$. IS1 is closest to the track of the satellite and IS7 is farthest away. When acquired simultaneously, each IS views a different area across track. A series of days is required to get all IS positions for the same ground location.

The other new feature of the ASAR of interest for soil moisture is the alternating polarization (AP) mode. In this mode, two polarization combinations (ERS had only VV) can be obtained (VV and $\mathrm{HH}, \mathrm{HH}$ and $\mathrm{HV}$, or $\mathrm{VV}$ and $\mathrm{VH}$ ). It is anticipated that this additional information will enhance soil moisture retrieval. Swath width is nominally $100 \mathrm{~km}$, and the product pixel size is $30 \mathrm{~m}$.

A limited number of data products is available in dual polarization mode. Those of interest include the Alternating Polarization Mode Precision Image and Alternating Polarization Ellipsoid Geocoded Image. Each will be a nominal 100 x $100 \mathrm{~km}$ scene with a pixel spacing of 12.5 x $12.5 \mathrm{~m}$ and a pixel size of 30 x $30 \mathrm{~m}$. The Alternating Polarization Ellipsoid Geocoded Image is resampled to a North orientation and georectified. 
Table 13. Specifications for ASAR Image Mode Swaths

\begin{tabular}{|l|c|c|c|}
\hline \multicolumn{1}{|c|}{ Image Swath } & Swath Width (km) & $\begin{array}{c}\text { Ground, position } \\
\text { from nadir (km) }\end{array}$ & $\begin{array}{c}\text { Incidence Angle } \\
\text { Range }\end{array}$ \\
\hline IS1 & 105 & $187-292$ & $15.0-22.9$ \\
\hline IS2 & 105 & $242-347$ & $19.2-26.7$ \\
\hline IS3 & 82 & $337-419$ & $26.0-31.4$ \\
\hline IS4 & 88 & $412-500$ & $31.0-36.3$ \\
\hline IS5 & 64 & $490-555$ & $35.8-39.4$ \\
\hline IS6 & 70 & $550-620$ & $39.1-42.8$ \\
\hline IS7 & 56 & $615-671$ & $42.5-45.2$ \\
\hline
\end{tabular}

In general, the VV-VH combination is preferred for soil moisture retrieval. The IS2 provides continuity of the ERS observations. The IS1-IS3 may better minimize roughness effects, while the IS4-IS6 may provide more vegetation information. Data takes must be scheduled and are limited to approved investigations. Coverage of the SMEX05/POLEX sites concurrent with ground data collection will be requested. Several coverages are available.

The MERIS system on Envisat may be of value. It is a $68.5^{\circ}$ field-of-view pushbroom imaging spectrometer that measures the solar radiation reflected by the earth, at a ground spatial resolution of $300 \mathrm{~m}$, in 15 spectral bands (412.5, 442.5, 490, 510, 560, 620, 665, 681.25, 705, 753.75, 760, 775, 865, 890, and $900 \mathrm{~nm}$ ), programmable in width and position, in the visible and near infra-red. The instrument has a very wide swath, which results in frequent coverage. MERIS allows global coverage of the earth in 3 days. MERIS data cannot be obtained at the same time as ASAR image products.

\subsubsection{Terra Sensors}

The NASA Terra spacecraft (http://terra.nasa.gov/About/) includes several instruments of value to the soil moisture investigations proposed here. Of particular interest are the MODIS and advanced spaceborne thermal emission and reflection radiometer (ASTER).

MODIS is on both the Terra and Aqua satellites (http://modis.gsfc.nasa.gov). The Terra satellite has a descending orbit that crosses the equator about 10:30 a.m. LST, and the Aqua satellite has an ascending equatorial crossing time of 1:30 p.m. LST. Coverage of a single location varies with the orbital path, so coverage can be either daily or every other day. The angle of incidence varies depending on the orbital path from $-55^{\circ}$ to $55^{\circ}$ for a swath of $2330 \mathrm{~km}$. The bands of MODIS are listed in Table 14. Most of the imagery from MODIS is provided by the NASA Goddard Space Flight Center Distributed Active Archive Center. Surface reflectance for bands 1-7 are provided as product MOD 09, which has (1) an atmospheric transmittance correction, (2) a view angle correction for bidirectional reflectance distribution function, and (3) a cloud mask. The data are not corrected for topography. 
Table 14. MODIS Bands

\begin{tabular}{||l|l|l|l||}
\hline \multicolumn{1}{|c|}{ Primary Use } & \multicolumn{1}{c|}{ Band(s) } & \multicolumn{1}{c|}{ Wavelength } & \multicolumn{1}{c|}{ Pixel Size } \\
\hline Vegetation index & 1 & $620-670 \mathrm{~nm}$ & $250 \mathrm{~m}$ \\
\hline Vegetation index & 2 & $841-876 \mathrm{~nm}$ & $250 \mathrm{~m}$ \\
\hline & $3459-479 \mathrm{~nm}$ & $500 \mathrm{~m}$ & \\
\hline & $4545-565 \mathrm{~nm}$ & $500 \mathrm{~m}$ & \\
\hline Vegetation $\mathrm{H}_{2} \mathrm{O}$ & 5 & $1230-1250 \mathrm{~nm}$ & $500 \mathrm{~m}$ \\
\hline Vegetation $\mathrm{H}_{2} \mathrm{O}$ & 6 & $1628-1652 \mathrm{~nm}$ & $500 \mathrm{~m}$ \\
\hline & 7 & $2105-2155 \mathrm{~nm}$ & $500 \mathrm{~m}$ \\
\hline Ocean color & $8-16$ & $405-877 \mathrm{~nm}$ & $1000 \mathrm{~m}$ \\
\hline Atmospheric $\mathrm{H}_{2} \mathrm{O}$ & $17-19$ & $890-965 \mathrm{~nm}$ & $1000 \mathrm{~m}$ \\
\hline Thermal & $20-363.660-$ & $14.385 \mathrm{~m}$ & $1000 \mathrm{~m}$ \\
\hline
\end{tabular}

Other MODIS data products of interest are land cover type (MOD 12), vegetation indices (MOD 13), leaf area index (MOD 15), evapotranspiration (MOD 16), net primary production (MOD 17), and land surface temperature (MOD 11), which are composited to produce a cloudfree image at $1000 \mathrm{~m}$ pixel resolution every 10 days.

ASTER provides high-resolution visible (VIR, shortwave infrared [SWIR], and thermal infrared [TIR] data on request [see Table 15]). Coverage is only obtained on request, and they are prioritized. In general, the data coverage occurs on the same day as Landsat 7 for a $60-\mathrm{km}$ swath.

MODIS (Terra) and ASTER coverage dates during CLASIC are shown in Table 15.

Table 15. Characteristics of the ASTER sensor systems

\begin{tabular}{||l|l|l|l||}
\hline \multicolumn{1}{|c|}{ System } & \multicolumn{1}{|c|}{ Channel } & \multicolumn{1}{c|}{$\begin{array}{c}\text { Spectral } \\
\text { Range }(\boldsymbol{\mu m})\end{array}$} & $\begin{array}{c}\text { Spatial Resolution } \\
(\mathbf{m})\end{array}$ \\
\hline VIR & 1 & $0.52-0.60$ & 15 \\
\hline 2 & $0.63-0.69$ & \\
\hline 3N & $0.78-0.86$ & \\
\hline 3B & $0.78-0.86$ & \\
\hline SWIR & 4 & $1.60-1.70$ & 30 \\
\hline 5 & $2.145-2.185$ & \\
\hline 6 & $2.185-2.225$ & \\
\hline 7 & $2.235-2.285$ & \\
\hline 8 & $2.295-2.365$ & \\
\hline 9 & $2.360-2.430$ & \\
\hline TIR & $8.125-8.475$ & 90 \\
\hline 11 & $8.475-8.825$ & \\
\hline 12 & $8.925-9.275$ & \\
\hline 13 & $10.25-10.95$ & \\
\hline 14 & $10.95-11.65$ & \\
\hline
\end{tabular}




\subsubsection{Landsat Thematic Mapper}

The TM satellites collect data in the visible and infrared regions of the electromagnetic spectrum. Data are high-resolution $(30 \mathrm{~m}$ ) and are valuable for mapping land cover and vegetation parameters. Additional details on the Landsat program and data can be found at http://landsat7.usgs.gov/programdesc.html.

Presently, Landsat 5 is still operating and, following a problem, Landsat 7 is now providing modified products. An instrument malfunction occurred onboard Landsat 7 on May 31, 2003. The problem was caused by failure of the Scan Line Corrector (SLC), which compensates for the forward motion of the satellite. The problem is permanent and results in an up to 25 percent data loss per scene. The Landsat 7 Enhanced Thematic Mapper Plus (ETM+) is still capable of acquiring useful image data with the SLC turned off, particularly within the central portion of any given scene (about $22 \mathrm{~km}$ ). These data are still acquired and are referred to as "SLC-off" mode. SLC enhanced products are also now available that use interpolation schemes to fill missing data gaps. These can be based on pre-loss of SLC scenes or other dates.

\subsubsection{Advanced Wide Field Sensor}

The advanced wide field sensor (AWiFS) is a moderate-spatial resolution sensor on board the Resourcesat-1 satellite from the Indian Remote Sensing Program (launched October 17, 2003). Data are available from Space Imaging (Thornton, Colorado). AWiFs has a swath of $740 \mathrm{~km}$, which gives it a higher temporal repeat frequency than Landsat or Aster, but less than MODIS on Terra and Aqua. The pixel size for AWiFS data is $56 \mathrm{~m}$. Quarter scenes (or quads, $370 \mathrm{~km}$ by $370 \mathrm{~km}$ ) have been ordered for SMEX05/POLEX, which are within $55^{\circ}$ zenith angle of the study area center point, to provide the potential for weekly coverage. Characteristics of AWiFS are presented in Table 16.

Table 16. Characteristics of the AWiFS system

\begin{tabular}{||l|l||}
\hline Equatorial crossing & $10: 30$ a.m. \\
\hline Orbit height & $817 \mathrm{~km}$ \\
\hline Swath width $(\mathrm{km})$ & $740 \mathrm{~km}$ \\
\hline Orbit Inclination & $98.7^{\circ}$ \\
\hline Number of orbits per day & 14 \\
\hline Spatial resolution (m) & 56 \\
\hline Spectral bands (micron) & $0.52-0.59$ \\
& $0.62-0.68$ \\
& $0.77-0.86$ \\
\hline
\end{tabular}

\subsection{Aircraft-Based Microwave Remote Sensing of Soil Moisture}

The PSR is an airborne microwave imaging radiometer operated by the NOAA Environmental Technology Laboratory (Piepmeier and Gasiewski 2001) for obtaining polarimetric microwave emission. It has been used successfully in several major experiments including SGP99 (Jackson et al. 2002), SMEX02, and SMEX03. 
A typical PSR aircraft installation is composed of the following four primary components:

- Scanhead - houses the PSR radiometers, antennas, video and IR sensors, A/D sampling system, and associated supporting electronics. The scanhead can be rotated in azimuth and elevation to any arbitrary angle. It can be programmed to scan in one of several modes, including conical, cross-track, along-track, and spotlight.

- Positioner - supports the scanhead and provides mechanical actuation, including views of ambient and hot calibration targets.

- Data acquisition system - consists of a network of four computers that record several asynchronously sampled data streams, including navigation data, aircraft attitude, scanhead position, radiometric voltage, and calibration target temperatures. These streams are available in-flight for quick-look processing.

- Software for instrument control and operation.

The PSR/CX scanhead will have the polarimetric channels listed in Table 17. The system will be operated in two imaging modes, both using conical scanning. Mapping characteristics are described in Table 18.

At the end of each set of flight lines, a steep (approximately $60^{\circ}$ ) port roll will be requested for calibrating the PSR radiometers using cold sky looks. Additional details on the PSR not presented here can be found at http://www1.etl.noaa.gov.

Table 17. PSR/CX Channels for SMEX04

\begin{tabular}{|l|c|c||}
\hline \multicolumn{1}{|c|}{ Frequency (GHz) } & Polarizations & Beamwidth \\
\hline $5.82-6.15$ & $\mathrm{~V}, \mathrm{~h}$ & $10^{\circ}$ \\
\hline $6.32-6.65$ & $\mathrm{~V}, \mathrm{~h}$ & $10^{\circ}$ \\
\hline $6.75-7.10$ & $\mathrm{v}, \mathrm{h}, \mathrm{U}, \mathrm{V}$ & $10^{\circ}$ \\
\hline $7.15-7.50$ & $\mathrm{~V}, \mathrm{~h}$ & $10^{\circ}$ \\
\hline $10.6-10.8$ & $\mathrm{v}, \mathrm{h}, \mathrm{U}, \mathrm{V}$ & $7^{\circ}$ \\
\hline $10.68-10.70$ & $\mathrm{~V}, \mathrm{~h}$ & $7^{\circ}$ \\
\hline $9.6-11.5 \mathrm{um} \mathrm{IR}$ & $\mathrm{V}+\mathrm{h}$ & $7^{\circ}$ \\
\hline
\end{tabular}

Table 18. PSR Flightline and Mapping Specifications for SMEX04

\begin{tabular}{||l|l||}
\hline Altitude (AGL) in $\mathrm{m}$ & 7300 \\
\hline Number of parallel flight lines & 4 \\
\hline Flight line length $(\mathrm{km})$ & 150 \\
\hline Flight line spacing $(\mathrm{km})$ & 19 \\
\hline Scan period (seconds) & 8 \\
\hline Incidence angle (deg) & 55 \\
\hline 3-dB footprint resolution & $3.0 \mathrm{~km}$ at $6 \mathrm{GHz}$ \\
\hline
\end{tabular}




\section{References}

Bindlish, R, TJ Jackson, A Gasiewski, M Klein, and EG Njoku. 2006. "Soil moisture mapping and AMSR-E validation using the PSR in SMEX02.” Remote Sensing of Environment, 103:127139.

Bolten, JD, V Lakshmi, and E Njoku. 2003. "Soil moisture retrieval using the passive/active L and S- band radar/radiometer.” IEEE Transactions on Geoscience and Remote Sensing, 41:2792-2801.

Gaiser, PG, KM St. Germain, EM Twarog, GA Poe, W Purdy, D Richardson, W Grossman, WL Jones, D Spencer, G Golba, J Cleveland, L Choy, RM Bevilacqua, and PS Chang. 2004. "The windsat spaceborne polarimetric radiometer: sensor description and early orbit performance.” IEEE Transactions on Geoscience and Remote Sensing, 42:2347-2361.

Jackson, TJ. 1997. "Soil moisture estimation using special satellite microwave/imager satellite data over a grassland region.” Water Resources Research, 33:1475-1484.

Jackson, TJ, AY Hsu, and PE O’Neill. 2002. “Surface soil moisture retrieval and mapping using high-frequency microwave satellite observations in the Southern Great Plains.” Journal of Hydrometeorology, 3:688-699.

Kustas, WJ, and TJ Jackson. 1999. "The impact on area-averaged heat fluxes from using remotely sensed data at different resolutions: A case study with Washita '92 data." Water Resources Research, 35:1539-1550.

Li, L, EG Njoku, E Im, PS Chang, and K St. Germain. 2004. “A preliminary survey of radiofrequency interference over the U.S. in Aqua AMSR-E data." IEEE Transactions on Geoscience and Remote Sensing, 42:380- 390.

Narayan, U, V Lakshmi, and EG Njoku. 2004. "Retrieval of soil moisture from passive and active L/S band sensor (PALS) observations during the soil moisture experiment in 2002 (SMEX02).” Remote Sensing of Environment, 92:483-496.

Njoku, EG, W Wilson, S Yueh, T Jackson, V Lakshmi, and JD Bolten. 2003. “Observations of soil moisture using a passive and active low-frequency microwave airborne sensor during SGP99.” IEEE Transactions on Geoscience and Remote Sensing, 40:2659-2673.

Piepmeier, JR, and AJ Gasiewski. 2001. "Digital correlation microwave polarimetry: analysis and demonstration.” IEEE Transactions on Geoscience and Remote Sensing, 39:2392-2410.

Teng, WL, JR Wang, and PC Doraiswamy. 1993. "Relationship between satellite microwave radiometric data, antecedent precipitation index, and regional soil moisture.” International Journal of Remote Sensing, 14:2483-2500. 